\title{
Sociedade civil e prevenção de riscos hidro-climáticos na Amazônia sul-ocidental: uma abordagem neo-sistêmica
}

\section{Civil society and prevention of hydro-climate risks in Southwestern Amazon: a neo-systemic approach}

\author{
Kleverton Melo de Carvalho ${ }^{1 *}$, Maria Elisabete Pereira dos Santos ${ }^{2}$, Eduardo Sonnewend \\ Brondizio $^{3}$, Rosinadja Batista dos Santos Morato ${ }^{1}$, Denival Dias de Souza ${ }^{1}$, Janaina Andrade de \\ Cerqueira Teles ${ }^{1}$, Edna Maria de Andrade Alves Dias ${ }^{4}$
}

\begin{abstract}
RESUMO
Este artigo discute a interveniência da sociedade civil na prevenção de riscos hidro-climáticos na Amazônia sul-ocidental, a partir de uma abordagem neo-sistêmica, no Acre, que tem sido palco de enchentes e de incêndios recorrentes e vem se adaptando a este cenário através de uma estrutura de prevenção. De natureza qualitativa e exploratória, este estudo de caso foi construído a partir de levantamento documental e de campo, sendo mapeados e entrevistados 34 gestores de diferentes organizações públicas relacionadas à questão hídrica e climática. Através de análise do conteúdo, os dados permitiram identificar que o Acre enfrentou três grandes ciclos: o de formação do sentido ambientalista; o de diferenciação e estabilização da estrutura, com a presença de iniciativa civil de natureza técnica; o de possível ruptura, ou de riscos às práticas de mitigação. $\mathrm{O}$ trabalho conclui que a comunicação facilitada do risco tem sido um dos principais avanços das políticas de prevenção no Acre e isso guarda expressiva relação com a articulação civil; existe uma mudança em curso na orientação mais ambientalista da sociedade acreana que coloca em risco a própria estrutura de prevenção estabelecida.
\end{abstract}

Palavras-chave: Sociedade civil; Prevenção de riscos hidro-climáticos; Amazônia sul-ocidental.

\begin{abstract}
This paper discusses the intervention of civil society in the prevention of hydro-climatic risks in the southwestern Amazon, from a neo-systemic approach. The state of Acre has been the scene of flooding and large recurrent fires and has been adapting to this scenario using a prevention structure. Due to its qualitative and exploratory nature, this case was built from a documentary and field research, which mapped and interviewed 34 managers from different public organizations related to water and climate issues. The data was treated using a content analysis technique. As main insights, we identified that Acre faced three major cycles: the formation of the environmentalist sense; the differentiation and stabilization of the structure, with the presence of civil initiative of a technical nature; possible disruption or risk to mitigation practices. The paper concludes that: facilitated risk communication has been one of the main advances of prevention policies in Acre and this has a significant relationship with civil articulation; There is an ongoing change in the more environmentalist orientation of the Acrean society that endangers the prevention structure that has been established.
\end{abstract}

Keywords: Civil Society; Prevention of hydro-climatic risks; Southwestern Amazon.

\footnotetext{
${ }^{1}$ Universidade Federal de Sergipe (Prodema, Profiap, PPGS). *kleverton1 @ academico.ufs.br

${ }^{2}$ Universidade Federal da Bahia (NPGA/EAUFBA).

${ }^{3}$ Indiana University (IU/Casel/EUA).

${ }^{4}$ Pontifícia Universidade Católica do Rio Grande do Sul (PUCRS)
} 


\section{INTRODUÇÃO}

O presente artigo discute a interveniência da sociedade civil na prevenção de riscos hidro-climáticos na Amazônia sul-ocidental, notadamente no Acre, a partir de uma abordagem neo-sistêmica. Por riscos hidro-climáticos se entendem aqueles que, especialmente associados às atividades humanas, resultam das mudanças do clima, afetando sistemas e regiões naturais e humanas do planeta (IPCC, 2013; HOPKIN, 2017). A prevenção ao risco tem sido primordialmente discutida na literatura com base em duas perspectivas: a do risco real, mensurado tecnicamente, e a do risco em uma dimensão mais simbólica e subjetiva. Aqui propomos um olhar epistemológica e metodologicamente integrado, que sem desconsiderar riscos reais e subjetivamente percebidos, examina-os como parte da evolução dos sistemas sociais.

Defendemos a tese de que a sociedade civil tem exercido um importante papel no processo sistêmico-evolutivo da gestão da prevenção no estado do Acre, influenciando as estruturas sistêmicas como resposta ao risco, considerando sua singularidade de padecer com estiagens intensas e cheias que afetam parcela significativa de sua população, tendo como resposta uma sociedade civil envolvida nas políticas governamentais de prevenção. A experiência acreana pode trazer pistas sobre uma rede de fatores sistêmicos imbricados que envolve não apenas as emergências hidro-climáticas de per se, mas uma cadeia de decisões que ampliam ou reduzem o cenário de riscos, nas práticas de prevenção. Compreender a interveniência da sociedade civil no contexto de tais fatores pode subsidiar a concepção de políticas de prevenção mais eficientes para a Amazônia.

De natureza qualitativa e exploratória, o artigo configura-se como um estudo de caso, tendo sido entrevistadas trinta e 34 que atuam em organizações públicas no estado, oriundas do movimento socioambiental e militantes da Iniciativa MAP (acrônimo de Madre de Deus, Acre e Pando, estados transfronteiriços da Amazônia sul-ocidental), sendo os dados tratados através da técnica análise de conteúdo. O trabalho se subdivide em quatro partes. A primeira trata dos fundamentos neo-sistêmicos relacionados ao risco. A segunda detalha os caminhos metodológicos adotados. A terceira discute os resultados empíricos e a quarta traz as conclusões. 


\section{FUNDAMENTOS NEO-SISTÊMICOS DO RISCO}

A produção teórica sobre a dimensão social do risco é emergente e tem caminhado em várias direções. Giddens (2013) afirma que os riscos decorrem de ações que se repetem ao longo do tempo e em determinados espaços. De maneira similar, Beck (2016) considera que o risco se configura como uma exposição voluntária e deliberada a determinadas situações, levando as sociedades modernas a se tornarem sociedades do risco, mediante mecanismos de percepção e da decodificação discursiva de ameaças existentes. Ambos autores consideram o processo de industrialização e do capitalismo como vetores da ampliação do cenário de riscos.

Apesar da relevância de Beck e Giddens nesse debate, Lupton (2013) tem refutado as contribuições desses autores, para quem as pessoas tendem a ser posicionadas como elementos que reagem automaticamente e de maneira individual aos riscos. A autora propõe uma abordagem social construtivista, sustentando que os riscos seriam conglomerados de significados simbólicos, lógicas e crenças que existem em torno de fenômenos reais, dando a esses fenômenos forma e substância (LUPTON, 2013).

Para explorar o fenômeno do risco, advogamos que a abordagem neo-sistêmica desenvolvida pelo sociólogo alemão Niklas Luhmann traz expressivas luzes para uma ampliação no olhar sobre essa questão. Para Luhman $(2007 ; 2016)$ o risco decorre do processo decisório no âmbito da evolução dos sistemas sociais, por gerar perigos para os mais diversos envolvidos. Para subsidiar o trabalho empírico, debatemos dois aspectos dentro da teoria adotada: indivíduos e formação dos sistemas sociais; riscos, prevenção e participação social.

Indivíduos e formação dos sistemas sociais. A visão de Luhmann sobre os sistemas sociais se diferencia da comumente adotada pela teoria organizacional. A sociedade não é a humanidade, mas um sistema de comunicação, e os sistemas sociais são abstrações para simplificar a realidade. Uma operação genuinamente social é aquela fundamentada no processo comunicativo, que envolve um grande número de pessoas, ou consciências, que formam sistemas chamados de "psíquicos" no entorno dos sistemas sociais, possuindo seus próprios processos e estruturas (LUHMANN, 2013; 2016).

As consciências representam o ponto de partida para a geração e operação dos sentidos, que são uma espécie de "identidade" e limite de cada sistema social, representando escolhas e preferências em meio à complexidade. $\mathrm{O}$ sentido faz o sistema converter caos em estrutura. Todo sistema social tem sua função e é esta que determina a 
estrutura, impulsionada pelo sentido. Existe um processo de interpenetração entre sistemas psíquicos e sociais dentro de um sentido comum, que permite o sistema social evoluir em um ambiente complexo. De fato, o último existe devido à existência do primeiro. O processo de comunicação entre sistemas psíquicos e sociais somente é possível graças ao fenômeno da dupla contingência, ou expectativas mútuas, que gera interações (NEVES, 2005; LUHMANN, 2012; 2013; VIDAL, 2015).

A comunicação é, também, o elemento central de uma intrincada rede de operações internas chamadas de autopoiese, envolvendo contínua produção sistêmica de si mesmo, como parte de um processo construtivista e evolutivo. Por esse caminho, os sistemas sociais se diferenciam em funções que em seu âmbito englobam diferentes sistemas organizacionais. A função do sistema político é estabelecer decisões coletivas vinculantes, cuja comunicação se manifesta através do poder. Dele deriva o sistema jurídico, tornando lícito aquilo que representa expectativas normativas que se generalizam. O sistema econômico trata da produção e regulação da escassez, e suas decisões norteiam o sistema político (RODRIGUES; NEVES, 2012; LUHMANN, 1982; 2013; 2016; 2018).

Riscos, prevenção e participação social. O risco é parte importante da construção de um sistema social e é fruto de múltiplas contingências sociais e de intervenções e pressões. A prevenção é a mediação entre decisão e risco, sendo a preparação para perdas incertas e a tentativa de reduzir probabilidades e impactos. Neste contexto, exercem importante papel a comunicação do risco, a adesão das consciências e a interveniência dos tomadores de decisão. Risco se diferencia de perigo. Esse último mais se relaciona aos fenômenos naturais ou aos resultados de decisões tomadas. Assim, o risco remete a uma ideia de contingência não apenas pela escolha, mas pela possibilidade de ser evitado, não existindo nenhuma conduta livre de riscos (LUHMANN, 2005).

A visão construcionista luhmanniana propõe a existência de uma árvore decisória imbricada ao risco, sendo este um construto a ser discutido pela teoria organizacional. $\mathrm{O}$ enfoque neo-sistêmico parece preencher uma lacuna no âmbito da visão mais geral do risco. Por esse caminho, concordamos com Carvalho (2019), que propõe um modelo integrado para lidar com os riscos, conforme Figura 1 (a seguir). Os riscos reais pressionam indivíduos, gerando sentidos no âmbito da subjetividade individual, conforme contribuições de Giddens (2013) e Beck (2016), impulsionando-os a agir coletivamente 
para prevenção, em consonância ao modelo proposto por Lupton (2013). Tais pressões pressupõem riscos decisórios que podem representar perigos ou podem gerar uma evolução para que os sistemas envolvidos confluam para práticas de prevenção.

Figura 1 - Modelo integrado do risco

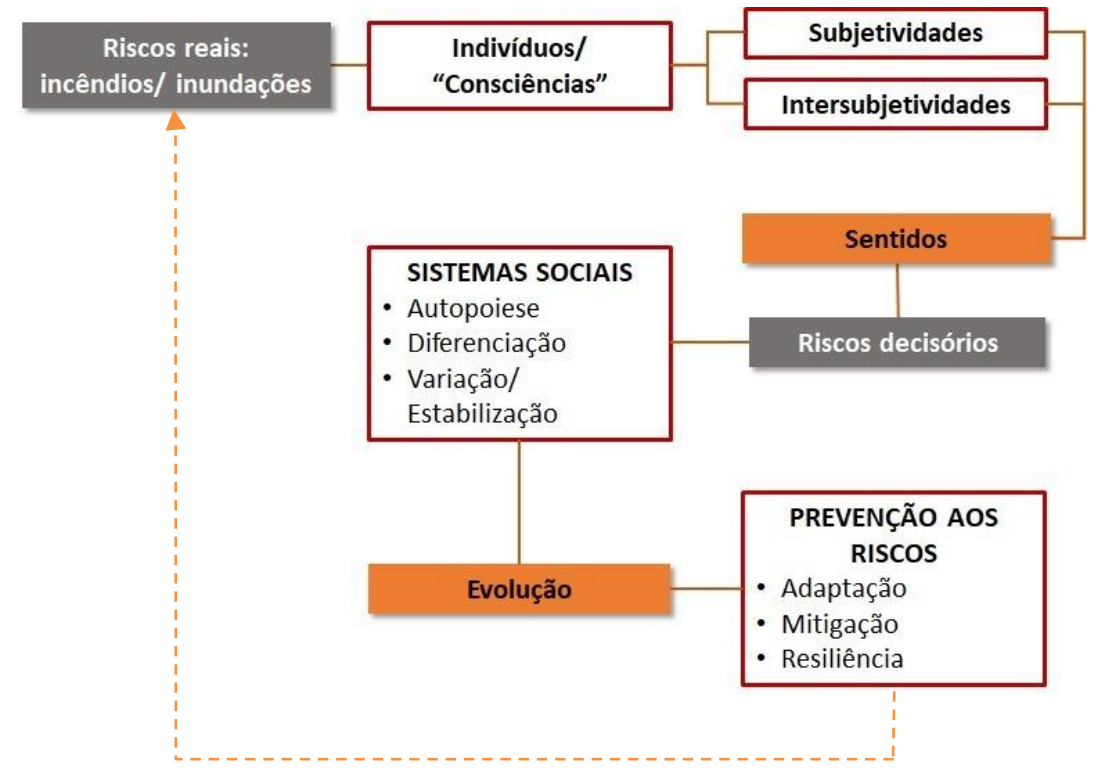

Fonte: Adaptado de Carvalho (2019)

Neste âmbito, ocorre um processo autopoiético que envolve o sistema psíquico. Os sentidos são integrados no processo de interpenetração e se expandem dentro do sistema a partir da comunicação que é incorporada e interpretada à luz de conflitos. A contextualidade das interações favorece a autopoiese e ajudam a formar redes sociais mais complexas. Em um sistema de interação conflituosa, cada novo movimento de comunicação é enquadrado dentro do conflito e isso tem especial relevo no âmbito do sistema político. Para que a comunicação sobre o risco proporcione consensos dentro de um sistema deve haver uma transição do poder de decisão do regulador para as partes interessadas. Os riscos decisórios mostram-se ampliados quando os posicionamentos das partes envolvidas diferem fundamentalmente - uma parte tomando as decisões e a outra sendo exposta aos perigos dessas decisões (LUHMANN, 2005, 2016; BOHOLM, 2015; VIDAL, 2017).

A participação da sociedade civil e as estruturas que algumas vezes decorrem dessa participação podem representar respostas sistêmicas ao risco. $\mathrm{O}$ desenvolvimento de um conceito neo-sistêmico para sociedade civil não foi exatamente parte do esforço teórico de Luhmann, para quem a comunicação representa o verdadeiro eixo estruturante dos sistemas sociais. Mas o sociólogo qualifica a sociedade civil organizada como um subsistema político importante, por pressionar decisões políticas que envolvem riscos. 
Em especial, dedica atenção à opinião pública, que se configura como uma rede de comunicações cujos efeitos podem gerar uma perda duradoura de orientação e mudanças nos sentidos do sistema político, com consequente alteração das estruturas. Em tal decurso comunicativo, o sistema midiático exerce um papel fundamental (LUHMANN, 2005; 2010; BOHOLM, 2015).

\section{DESENHO METODOLÓGICO}

Nossa pesquisa pode ser considerada qualitativa e exploratória quanto aos seus fins, revelando indícios, sem buscar resultados definitivos e conclusivos (CRESWELL; CRESWELL, 2017) sobre a interveniência da sociedade civil na estrutura de prevenção, em uma perspectiva sistêmica. Trata-se, também, de um estudo de caso, caracterizado por possibilitar conclusões analíticas mais profundas sobre caso específico, permitindo a expansão da teoria adotada (YIN, 2015). Utilizamos levantamentos documental e de campo como meios e fontes de evidências. No primeiro, reportamo-nos a documentos oficiais. O segundo esteve centrado na seguinte sequência: definição dos respondentes e, pelo método bola de neve, mapeamento de respondentes-chave relacionados à questão hidro-climática; agendamento e realização das entrevistas presenciais. A modalidade bola de neve é particularmente útil para fins exploratórios (CRESWELL; CRESWELL, 2017).

Entrevistamos 34 gestores de organizações públicas, entre pessoas oriundas do movimento socioambiental do estado e militantes da Iniciativa MAP. Entre estes estiveram membros do Ministério Público, defesa civil, corpo de bombeiros, secretarias de meio ambiente, Agência Nacional de Águas, além de universidades. As entrevistas foram realizadas em maio e outubro de 2018, e tiveram a duração de 0:30 a 2:00h. Utilizamos um instrumento de pesquisa semiestruturado com questões norteadoras. Para preservar suas identidades, os entrevistados foram identificados pela letra E (de E1 a En).

Inspirados na técnica de análise do conteúdo de Bardin (2016), realizamos préanálise e seleção das falas que se mostraram mais relacionadas com as variáveis centrais da pesquisa. Em seguida identificamos as ideias centrais e realizamos uma revisão na categorização estabelecida, escolhendo os dados que se mostraram mais significativos.

Adotando um critério de categorização interpretativista e semântico, formamos temas com significados relacionados ao objeto analítico delineado (BARDIN, 2016; CRESWELL; CRESWELL, 2017), utilizando a teoria neossistêmica como filtro para formar proposições isoláveis. Sobre os documentos levantados, particularmente a 
legislação, percorremos as duas etapas iniciais (pré-análise e análise) e tomamos a decisão de utilizar diretamente os conteúdos mais pertinentes ao longo da discussão empírica.

\section{ACRE, SOCIEDADE CIVIL E PREVENÇÃO AOS RISCOS DE EVENTOS EXTREMOS}

Esta seção apresenta resultados empíricos e discussões, abordando três grandes ciclos no processo de formação da estrutura de prevenção, relacionados à participação da sociedade civil no Acre: o período de formação do ambientalismo; o período de estabilização, com a presença de iniciativa da sociedade civil de natureza técnica, no âmbito das estruturas burocráticas de prevenção; o período de possível ruptura, ou de riscos às práticas de mitigação. A Figura 2 traz uma representação gráfica das discussões empíricas do capítulo.

Figura 2 - Evolução do sistema de prevenção e sociedade civil no Acre

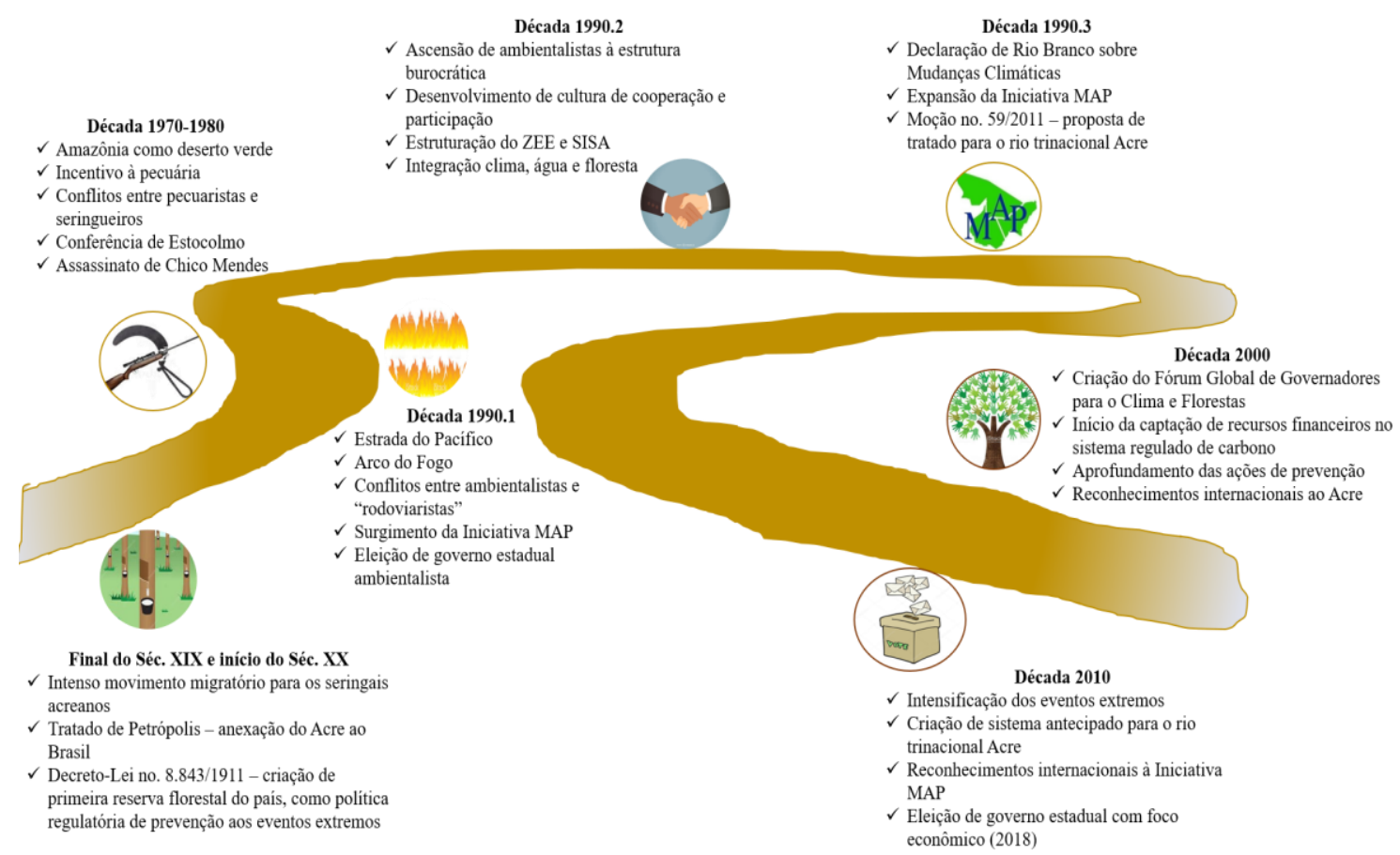

Fonte: Dados da pesquisa (2018)

O movimento extrativista e a formação do sentido ambientalista acreano. As raízes do sentido ambientalista acreano remontam o processo de formação do Acre:

$\mathrm{O}$ estado do Acre nasceu em uma região que já se relacionava com a economia globalizada. Isso iniciou com o ciclo da borracha, quando os brasileiros que exploravam o recurso iniciaram um conflito para que o território fosse anexado ao Brasil. Depois veio o segundo ciclo da borracha e de novo o Acre passou a ter relevância para a Segunda Guerra Mundial. O Acre era percebido como estratégico, mas perdeu relevância nas décadas seguintes. (EA4) 
Nos anos 70, o governo federal difundiu uma visão que a Amazônia seria um imenso deserto verde que precisaria ser ocupado, para iniciar uma série de políticas de ocupação, gerando lideranças locais que estimularam resistências. (EA12)

Diferentes ondas migratórias de brasileiros promoveram ocupação da região da bacia do rio Acre, para exploração dos seringais. Com a revolução industrial e o crescente mercado dos transportes, a produção extrativista da borracha entrou em franca expansão. No século XIX quase $60 \%$ da borracha consumida pelo mundo saía do Acre, que detinha uma imensa quantidade de seringais nativos. O sistema político e jurídico "Acre" foi criado com o Tratado de Petrópolis em um período que já havia preocupação com os eventos extremos na região (DECRETO-LEI No 8.843, 1911; VIANA, 1948).

No segundo ciclo da borracha, houve intensa campanha do governo federal para atender a necessidade da borracha brasileira na Segunda Grande Guerra. Com a decadência da atividade seringueira a Amazônia passou a ser percebida como deserto verde e região desocupada pelo governo federal, sobretudo entre o pós-guerra e a década de 70, havendo evidente interesse dos sistemas político e econômico brasileiro em desenvolver a pecuária (BRASIL - SENADO FEDERAL, 1911; VIANA, 1948; PONTES, 2014). Nesse cenário, emergiu o movimento ambientalista no Acre:

Uma das lideranças, o Chico Mendes, construiu uma trajetória ao perceber que o Brasil tinha dificuldades de incluir regiões periféricas, havendo um contexto de ocupação e conflitos fundiários. (EA10)

Há sinais de que a origem do movimento civil foi econômica - os seringueiros autônomos precisavam da floresta, o que logo foi se transformando em uma batalha política, envolvendo alianças com a sociedade civil, universidades e organizações nãogovernamentais. A Conferência de Estocolmo, que refletiu no Plano Nacional de Meio Ambiente brasileiro, ampliou a visibilidade nacional ao movimento (DELGADO, 2007):
O Chico trouxe o elemento social para a discussão ambiental, sendo um importante porta-voz do conceito do socioambientalismo. As sociedades que viviam nas florestas passaram a ser consideradas partes do sistema. Por força dos conflitos que ocorreram, o líder seringueiro decidiu buscar apoio de organizações financeiras multilaterais, conseguindo incluir na pauta salvaguardas e a consideração às comunidades locais para os projetos de financiamento, a ponto de isso chegar a ser discutido nas Nações Unidas. (EA4)

Houve clara interpenetração entre as representações dos seringueirosambientalistas e formulações do sistema político, com ampla ressonância nacional e internacional, resultando em um aumento de articulações civis em prol da sustentabilidade e a inclusão da questão social no debate ambiental. Encabeçando uma 
campanha contra projetos desenvolvimentistas de grande impacto na floresta, o líder seringueiro conseguiu aumentar as desapropriações locais e suspender novos empréstimos ao governo brasileiro por parte do Banco Mundial, ampliando enormemente as tensões contra os ambientalistas, o que culminou com seu assassinato (DELGADO, 2007):

A percepção da sociedade cresceu nesse momento, a partir da crise que a própria morte de Chico Mendes (em 1987) gerou como oportunidade para a questão ambiental. Quando o Relatório Brundtland foi lançado (em 1985) o Acre já se mobilizava em favor do meio ambiente. Havia no Acre um movimento de extrativistas que se alinhou ao movimento ambientalista, aos grandes eventos internacionais. Isso favoreceu a construção de novas regulações e politicas. (EA6)

Houve uma convergência sistêmica e histórica. Criou-se um hábito de valores ambientalistas no acreano e o reconhecimento de atores internacionais, surgindo uma sinergia. (EA12)

A ressonância internacional de sua morte ajudou a difundir e aprofundar o sentido ambientalista no âmbito do sistema político do estado. Percebemos no período pósassassinato do seringueiro uma etapa de profunda tensão política envolvendo o Acre, em especial envolvendo as obras de infraestrutura. A desapropriação de terras e assassinatos de indígenas, o desmatamento em áreas de exploração seringueira e a ampliação de incêndios dentro do conhecido "Arco do Fogo", com a extensão da BR 364 para conectar o Brasil ao Oceano Pacífico (CÂNDIDO, 2012; TOSTES, 2012) geraram um cenário de expressivo conflito entre o chamado "rodoviarismo" e o movimento socioambientalista (COSTA, ALONSO; TAMIOKA, 1999).

Como consequência dessa conjuntura, a sociedade civil acreana decidiu interpenetrar e promover um processo autopoiético no sistema político do estado, refletindo em uma estrutura de prevenção. Aqui discutiremos o surgimento de uma mobilização civil conhecida como Iniciativa MAP e a ascensão do grupo político apoiado por sindicatos, movimentos dos seringueiros e organizações não-governamentais ambientalistas ao governo do estado.

A participação da sociedade civil organizada: o papel da Iniciativa MAP. Um dos mais interessantes fenômenos relacionados à interpenetração e formação do sentido de proteção ao clima e às águas no Acre se deu com a chamada Iniciativa MAP, que é um movimento civil que surgiu como uma articulação de pesquisadores do Peru, Bolívia e Brasil, cujo nome é o acrônimo das três províncias transfronteiriças, Madre de Dios (Peru), Acre (Brasil) e Pando (Bolívia) (PERZ et al., 2019). 
Impulsionados pelos incêndios que assolavam o chamado "Arco do Fogo", na região da Estrada do Pacífico (extensão da BR 364), o movimento surgiu inicialmente para fazer frente aos riscos dos incêndios decorrentes da rodovia. A partir da Declaração de Rio Branco sobre Mudanças Globais, a mobilização foi se expandindo e se transformou em um movimento social envolvendo organizações relacionadas aos riscos hidro-climáticos inerentes à bacia do rio trinacional Acre, gerando um caso singular de governança transfronteiriça de natureza civil (PERZ et al., 2008; 2019):

Temos um sentimento comum - o de isolamento. Estamos distantes de nossos governos centrais e isso tem nos aproximado. Madre de Díos possui um descaso histórico por parte do governo em Lima e sofre terrivelmente com secas e enchentes. O mesmo ocorre com Pando e com o Acre. Não nos sentimos prioridade como estados federativos e isso nos une. Os costumes e a porosidade da fronteira nos fazem desejar a união. Nos sentimos irmanados. (EA24)

O rio Acre é um símbolo da união e é a coluna vertebral da Iniciativa MAP. Os eventos extremos aceleraram o desejo de aproximação e o processo de integração entre pessoas, a Rodovia Transoceânica findou que facilitou nossas interações, que vêm paulatinamente ocorrendo entre os diferentes serviços públicos subnacionais. (EA24)

Aqui no Acre temos experiências muito positivas sobre a água. A experiência do MAP é essencial para articulação com municípios do Rio Acre. Trabalhamos muitas questões que fazem interface com a água. (EA20)

A bacia passou a propulsionar uma mobilização social transfronteiriça em temas específicos, como saneamento, pesca, contaminação, saúde, engenharia, educação, atividades econômicas, águas, riscos e, sobretudo, eventos hidro-climáticos extremos, sendo este último fator uma das principais motivações para a cooperação. Com uma estrutura policêntrica, subdividida em grupos temáticos, os chamados Mini-MAPs, a Iniciativa MAP possui vínculos com centros de pesquisa e com órgãos relacionados ao clima e meio ambiente, produzindo dados climáticos para os três países. O movimento atua como um elemento catalisador da comunicação entre sociedade civil e governos, influenciando políticas públicas municipais e estaduais de maneira propositiva e multitemática (MENDOZA, 2015; PERZ et al., 2019).

Há uma contínua interpenetração da sociedade civil nas organizações públicas nos estados transfronteiriços para políticas de prevenção:

O mini-MAP gestão de riscos é o mais ativo, nas ações de prevenção e educação. Eles estão sempre planejando e executando, quando termina o período de inundação, já estão planejando o período de secas e incêndios. Há constantes simulados, um mapiense do Corpo dos Bombeiros do Acre desenvolveu uma metodologia de simulados, como 
jogos de mesa. E são constantes os treinamentos entre bombeiros e funcionários públicos do Peru e da Bolívia aqui no Acre. Os miniMAPs têm valores claros, de respeito e de uma constante interação entre mapienses e instituições nas quais eles estão vinculados. (EA24)

Cada mapiense tem como valor básico ser agente de transformação na causa climática e ambiental. Especialmente no mini-MAP gestão de riscos ocorre um fenômeno interessantíssimo. Como são integrados em uma contínua comunicação, quando há as calamidades, as defesas civis dos três países esquecem de que país estão vinculadas e passam a prestar socorro a todos. (EA24)

A Iniciativa MAP tem facilitado a comunicação do risco climático:

Temos cooperação com o INPE, com o ministério público. Temos expressiva atuação de pesquisadores ligados a Iniciativa MAP, buscando desenvolver metodologias próprias. Desenvolvemos encontros em Brasileia e Cobija (Bolívia), cidades transfronteiriças, entre polícias, defesa civil, universidades etc. Em nosso último trabalho saiu uma carta. A articulação se dá conforme as crises e a prevenção. A Iniciativa MAP é uma grande via de comunicação. (EA20)

A interpenetração do movimento tem ocorrido, também, no âmbito federal brasileiro:

Pudemos, com nosso trabalho, formalizar diversos avanços e expor nossos anseios para o Rio Trinacional Acre, que se materializou na moção de no. 59/2011. Neste documento expressamos a preocupação com os riscos climáticos e abrimos espaço para a criação de um acordo transfronteiriço para nossa bacia. (EA17)

A iniciativa foi o agente responsável direto pela elaboração moção de no. 59/2011, do Conselho Nacional de Recursos Hídricos da Agência Nacional de Águas do Brasil, com uma minuta de acordo transfronteiriço para o rio Acre entre os três países (MINISTÉRIO DO MEIO AMBIENTE, 2011). O movimento tem refletido em ações internacionais:

A própria Iniciativa MAP, muitos não sabem, é a semente do Fórum Global dos Governadores para Clima e Floresta, porque o Acre foi um dos pioneiros e agiu de maneira determinante nesse fórum internacional de governos subnacionais. (EA8)

O Fórum Global dos Governadores para Clima e Floresta foi uma iniciativa conjunta entre o Acre, o estado da Califórnia, nos Estados Unidos, e Chiapas, no México, envolvendo hoje 38 estados subnacionais sobre temas de cooperação para política climática, financiamentos, intercâmbio tecnológico e pesquisas (GOVERNORS' CLIMATE AND FORESTS TASK FORCE, 2019). Há, portanto, um reconhecimento internacional: 
A OTCA considerou o sistema de alertas que os três países desenvolveram uma experiência exitosa, no Foro de Aguas em Brasília, com possibilidades de replicação em outras regiões da Amazônia. (EA16)

A Organização do Tratado de Cooperação da Amazônia (OTCA) reconheceu os esforços da Iniciativa MAP no Foro Internacional de Águas em 2018 como um caso único. Por estes resultados, a Região MAP tem sido uma das contempladas pelo Projeto GEF Amazônia, da própria OTCA (OTCA, 2018). Faz-se prioritário destacar que o caso descrito de interpenetração da sociedade civil na estrutura governamental de prevenção foi resultado um ambiente político favorável, que favoreceu a adaptação e a estabilização de tal estrutura.

Adaptação e estabilização da estrutura de prevenção. A ampliação do sentido ambientalista na sociedade civil acreana favoreceu a eleição de um governo de coalizão com a o movimento ambientalista. O sistema político "Acre" foi conduzido por 20 anos pelo chamado "Governo da Floresta". O meio ambiente entrou na agenda governamental de maneira estratégica:

Quando o governo ascendeu 1999, muita gente do movimento ambientalista ascendeu a postos estratégicos no governo. Isso foi bom porque viabilizou as políticas que foram implantadas. (EA6)

Criou-se uma cultura de participação e de preocupação com o clima:

$\mathrm{O}$ acreano é muito ativo pelo meio ambiente. Eu acho que isso tem a ver com a história do Acre. Mesmo nossos indígenas, são muito ativos. (EA17)

Nós do SIPAM (Sistema de Proteção da Amazônia) temos uma admiração profunda pelo Acre, eles inseriram as questões climáticas na cultura do acreano, uma coisa muito diferente do que vemos em outros estados. As políticas climáticas passam de um governo para o outro. (EA33)

Isso parece ter refletido na estrutura:

O estado criou diversas comissões formadas por agentes públicos, privados e civis. Todos são voluntários. Isso faz parte de uma cultura desenvolvida. Há engajamento, as pessoas acreditam que o meio ambiente é importante. O Acre é como se fosse uma grande organização civil. (EA24)

Um fato importante de convergência entre governo, sociedade civil e iniciativa privada foi a elaboração do Zoneamento Ecológico Econômico (ZEE):

Essas políticas foram ganhando camadas e densidade. À medida que foram se adensando, tivemos a criação do ZEE na Fase 1, da política florestal, infraestrutura, condições de funcionamento dos entes públicos, muita capacitação. Abriu-se um diálogo entre governo, sociedade civil e iniciativa privada. (EA4) 
A experiência com a participação civil no ZEE foi a base para a criação do Sistema de Incentivos a Serviços Ambientais, através da Lei no. 2.308/2010, no qual a sociedade civil foi formalmente incluída na gestão:

Primeira coisa para o SISA ser viabilizado foi o marco institucional. A governança interna do SISA é bem robusta, com participação de instituições e representantes da sociedade civil. O braço executivo do SISA é um colegiado de três conselhos - meio ambiente, florestas e desenvolvimento rural sustentável, que representam 55 a 60 instituições, com 50\% de representantes da sociedade civil e 50\% de representantes do governo. (EA4)

Com o SISA, a estrutura de governança ambiental do estado convergiu para a prevenção aos riscos hidro-climáticos, tendo o Instituto de Mudanças Climáticas como um elemento central, conforme a Figura 3.

Figura 3 - Governança do Sistema de Incentivos a Serviços Ambientais

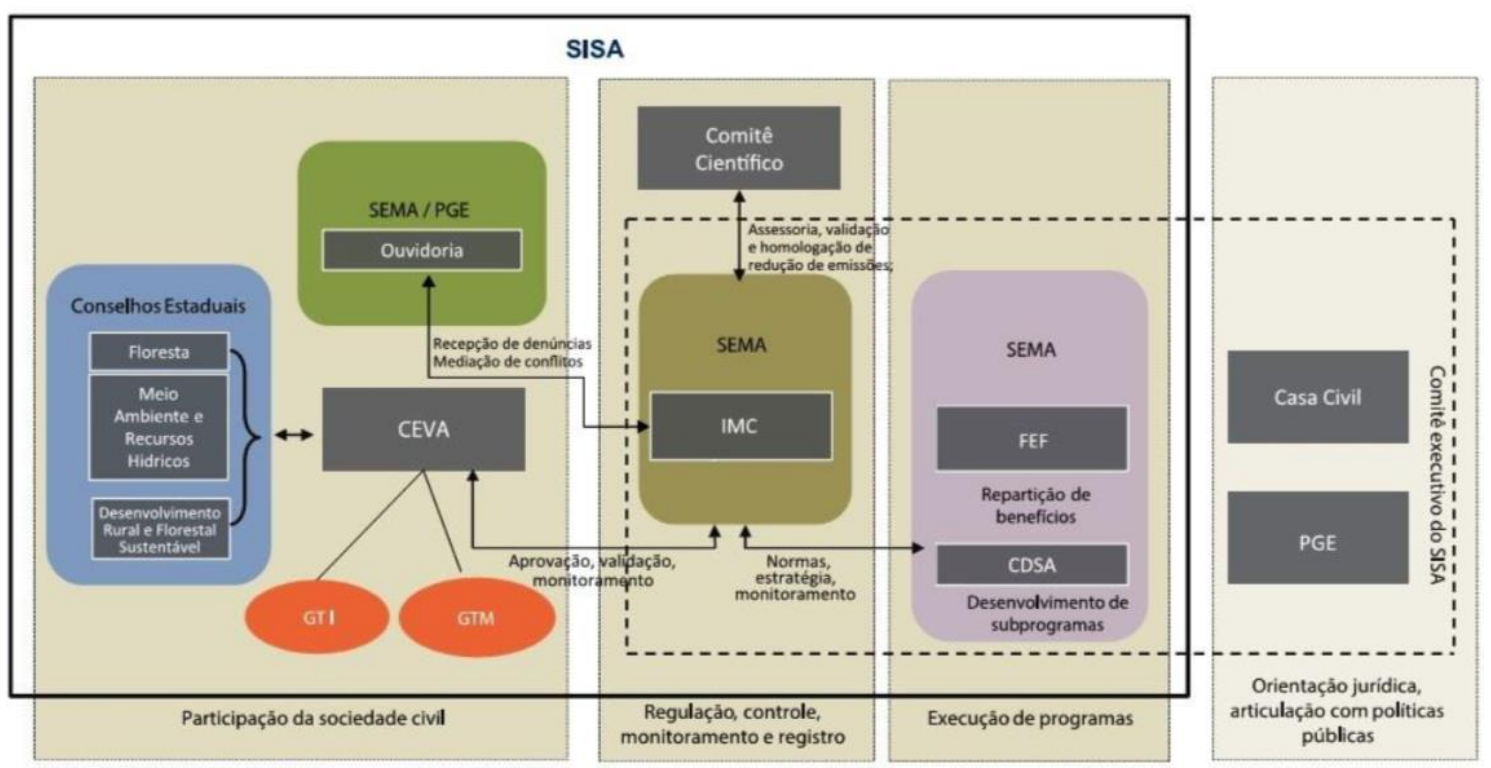

Fonte: Brasil. Câmara dos Deputados (2016)

O Acre desenvolveu uma estrutura formal de governança formada por conselhos estaduais, a Comissão Estadual de Validação e Acompanhamento (CEVA), o Instituto de Mudanças Climáticas (IMC), a Companhia de Desenvolvimento de Serviços Ambientais (CDSA), adotando uma postura regulatória jurisdicional, mediando conflitos de interesses entre atores, ampliando a capacidade para agir rapidamente nas emergências climáticas, envolvendo as administrações municipais acreanas e estados transfronteiriços do Peru e da Bolívia (BROSE, 2014; DUCHELLE et al., 2014; BRASIL, 2016).

O sentido ambientalista passou a considerar a questão climática como central, integrando clima, águas e floresta: 
O Acre vivencia um agravamento acelerado de enchentes e secas. Estou avaliando uma resposta da bacia e ela não responde apenas ao clima, ela responde também ao desmatamento. (EA1)

De fato, a sociedade civil acreana é enormemente impactada pelos eventos extremos:

Temos seis meses de chuvas e seis meses de secas. Nosso verão, em julho-agosto, há sempre focos de incêndios. Rio Branco é uma do ponto de encontro das correntes dos ventos, então a fumaça de toda região da Amazônia vai acumulando em nossa atmosfera local. (EA14)

Os dados sobre a magnitude das estiagens no Acre são alarmantes. Vale menção os incêndios de 2005 em mais de 470 mil hectares de floresta (prejuízos estimados em R\$ 470 milhões diretos e R \$ 3 bilhões indiretos, em serviços ambientais), em 2010 em 168 mil hectares e em 2019, com incêndios de grandes proporções em toda a Amazônia (ainda sem estimativa de prejuízos). Há uma confluência de fatores complexos que se somam, como poluição, aumento de ocupações ilegais, queimadas intencionais, bem como a construção de rodovias (BROSE, 2014; ESTADÃO, 2016; GLOBO, 2016; EXAME, 2019). As enchentes também são de expressiva magnitude:

O Estado todo é vítima de enchentes. A bacia do Rio Acre é capilarizada, ocorrendo enchentes generalizadas e periódicas. Quem mais sofrem são os ribeirinhos, na planície de inundação. (EA17)

Entre 2006 e 2015 os prejuízos com enchentes somaram cerca de 500 milhões de reais, um valor muito elevado para um estado que está entre os que menos arrecadam no Brasil e com grande vulnerabilidade social. Grande parte da população mais pobre reside nas margens dos rios. O Acre possui indicadores socioeconômicos que dão sinais de dificuldades para superar a pobreza. O estado possui um Índice de Desenvolvimento Humano (IDH) de 0,663, ocupando a 21o. posição no Brasil e 47,7\% dos acreanos estão abaixo da linha de pobreza (GOVERNO DO ESTADO DO ACRE, 2013; BROSE, 2014; BROWN, 2015; PEREIRA; SZLAFSZTEIN, 2016; ESTADÃO, 2016; GLOBO, 2016; VALOR ECONÔMICO, 2018; IBGE, 2018).

Em meio a esse cenário de avanços na estrutura de prevenção e dificuldades econômicas, um novo ciclo se apresenta no Acre. Novos sentidos parecem estar emergindo na sociedade civil, com possíveis reflexos nos sistemas envolvidos com a prevenção. Mudanças nos sentidos precedem mudanças propriamente ditas na estrutura dos sistemas sociais, conforme nos assevera Luhmann (2016). As lentes da teoria neossistêmica nos apontaram um processo de mudança que se mostra importante em nossa discussão. 


\section{Variação do sentido ambientalista na sociedade. O devir da prevenção no}

Acre. Há evidências que a visão política dos acreanos, caracterizada por ser ambientalista, tem passado por mudanças:

A imagem de Chico Mendes influenciou muito até certo período. De oito-dez anos para cá esse sentimento de "florestania", que era muito forte, foi adormecendo no Acre. E vem decaindo, talvez pela forte influência da mídia. (EA05)

A participação civil nos fóruns formais do SISA vem se reduzindo. A pressão da sociedade civil para a preservação da floresta e prevenção aos eventos extremos vem se atenuando e isso parece ser resultado da própria ascensão dos outrora participantes dos movimentos sociais ambientalistas às estruturas burocráticas do estado, aliado à perda na confiança de que o estado de fato possui uma preocupação ambiental, o que vem gerando redução no engajamento:

A ascensão dos ambientalistas ao poder enfraqueceu os movimentos sociais e as lideranças de base, houve um vácuo. Isso demora para se repor e temos dúvidas se surgirão outros líderes. A visão é que houve cooptação dessas lideranças e esvaziamento da pressão social legítima que as pessoas do atual governo costumavam fazer. (EA6)

Os fóruns de negociação têm perdido força, as pessoas têm se engajado menos. Esses fóruns foram muito importantes para uma intermediação de interesses no auge do movimento ambientalista. Hoje esses fóruns estão bem esvaziados, tendendo a parar por completo. As conquistas ambientais reduziram os próprios fóruns. Com a redução paulatina no desmatamento, as iniciativas civis esmaeceram. (EA6)

O debate ambiental funciona na estratosfera. Todo esse programa se institucionalizou no estado e na prática hoje ninguém apoia, percebemos esses programas estaduais como um discurso frágil. No fundo, eles não desejam nossa participação. (EA14)

Ao passo que se esvaziam as bases sociais e os fóruns de gestão ambiental e climática, um processo de mudança se observa na opinião pública. Há um claro avanço da cultura agro pop no Acre. De uma cultura extrativista, o acreano hoje percebe o domínio da natureza ao invés de preservá-la como algo mais moderno e o agronegócio como cultura, que se expressa em uma comunicação generalizada - culinária, eventos, artistas, música, propaganda na televisão e na moda:

Ao longo desses vinte anos a população foi avançando na cultura country. A cultura dominou o estado, hoje você entra no seringal e o cara está com cinto e o chapéu de vaqueiro. A cultura da pecuária e da agricultura extensiva cresceu e se tornou dominante e símbolo de força, status, riqueza. O movimento country findou tomando o poder nessas últimas eleições. (EA6) 
A ascensão do agronegócio é cultural, a cultura country se expressa no modo de vestir, nos cortes de cabelo, a música, nas relações sociais, o churrasco, o consumo da carne, até em ambientes não rurais. É um fenômeno econômico que se se fortalece ao se entranhar na cultura. Não é um por acaso todo esse processo. A campanha midiática do agro pop é fruto disso mesmo, a cultura absorvendo o viés econômico. O modelo está sendo instituído em todas as regiões do Brasil, salvaguardado pelos grandes eventos culturais, por artistas, pela moda, pela grande mídia e pelas bancadas legislativas. (EA4)

O country é tido como sinônimo de sucesso e tal sentido ajudou a alterar a estrutura do sistema político do estado, pelo voto direto - o governo eleito vem do agronegócio e representa esse movimento. Hoelle (2015) também observou o fenômeno de alteração cultural no Acre, sob as lentes da antropologia, chamando-o de "cultura do gado". Essa cultura tem perpassado as interações sociais de fazendeiros, peões, colonos agrícolas, seringueiros e servidores públicos:

A cultura country domina atualmente o estado. O Acre é rural e só tem duas cidades que são urbanas - Rio Branco e Cruzeiro do Sul. Todas as outras é formada por pessoas que vivem na cidade pequena, mas tem propriedades, com boizinhos ou alguma cultura agrícola. Mesmo os comerciantes, funcionários públicos, o prefeito, os vereadores, estão na cidade, mas estão plantando mandioca ou criando um "gadinho". O gado é a caderneta de poupança de quase todos, dá mais retorno que investimentos no sistema financeiro. (EA6)

Mesmo o outrora movimento ambientalista "de esquerda" hoje tem outra configuração:

O movimento popular de esquerda no meio rural não é mais a questão do meio ambiente, como já foi, mas questão da ocupação. Para esses movimentos, terra com floresta é terra improdutiva, nosso problema é muito maior com os pequenos do que com os grandes latifundiários, que não provocam incêndios. Os pequenos ocupam, invadem. Esses formam a esquerda campesina de hoje. (EA7)

E com a consolidação das alterações nos sentidos e mudanças políticas ocorridas nas últimas eleições, os respondentes sinalizaram riscos sistêmicos que envolvem a estrutura de prevenção que o Acre construiu nas últimas décadas:

O Acre se desenvolveu em outra lógica e agora possivelmente entraremos na lógica geral da Amazônia. (EA8)

Há riscos de voltarmos para os anos 1980, com o agravante de hoje termos uma pressão sobre o meio ambiente muito maior que antes. Pessoas esclarecidas simplesmente deixaram de pensar no meio ambiente. (EA27) 
Novos sentidos parecem nortear um processo autopoiético de mudanças, algo que ainda não se consolidou, mas que claramente emergiu como um possível novo caminhar para as políticas ambientalistas e climáticas do Acre.

\section{CONCLUSÕES}

Pode-se dizer que essa pesquisa atingiu seu objetivo central de discutir a interveniência da sociedade civil na prevenção de riscos hidro-climáticos na Amazônia sul-ocidental, notadamente no Acre, a partir de uma abordagem neo-sistêmica. Há significativos indícios que a sociedade civil no Acre exerceu, e ainda exerce, um importante papel no processo sistêmico-evolutivo de gestão da prevenção no estado. A identidade construída a partir da luta pelo território, pela terra e pela floresta, que remonta o início do século XX, concedeu aos acreanos um sentido de proteção à atividade econômica extrativista, que ao longo do tempo representou a proteção aos próprios ecossistemas. $\mathrm{O}$ estado enfrentou um processo de diferenciação intenso e passou por várias etapas. O antigo Áquiri (rio verde) iniciou com o sentido econômico de gerar renda para migrantes e impulsionado pelo sentido preservacionista tornou-se importante protagonista da preocupação climática.

No Acre, a comunicação do risco é facilitada pela presença constante de pesquisadores e participantes da Iniciativa MAP, o que ajudou a formar um sentido mais ambientalista na sociedade. O estudo confirmou a teoria de que os riscos impulsionam indivíduos envolvidos com a gestão prevenção, que tomam decisões no âmbito dos sistemas sociais. A participação da sociedade civil na escala local pode interferir na articulação entre organizações relacionadas aos riscos hidro-climáticos, gerando articulações maiores. Tais decisões também trazem consigo riscos imbricados.

No entanto, existe uma mudança em curso que coloca em risco a própria estrutura de prevenção desenvolvida e nisso percebemos como o sistema midiático, acoplado ao político e econômico, vem alterando a opinião pública e o outrora sentido ambientalista acreano. Os ventos de novas decisões pressionam o Brasil, reafirmando, sob muitos questionamentos, que o país tem destinação para o agronegócio. O Acre vivencia atualmente uma nova ruptura sistêmica. Ainda assim, acreditamos que os riscos políticos relacionados ao clima e às águas podem ser minimizados pela existência da Iniciativa MAP, cujos integrantes permanecem nas mais variadas organizações públicas e privadas, 
mantendo aceso o sentido ambientalista. Esse é um contexto que se desenha para novos estudos, dentro da abordagem neo-sistêmica que aqui adotamos.

\section{REFERÊNCIAS}

ACRE. Governo. Plano de Contingência Operacional de Enchente-2013. Rio Branco, AC, 2013.

BARDIN, L. Análise de Conteúdo. Lisboa, Portugal; Edições 70, LDA, 2016.

BECK, U. Sociedade de risco: rumo a uma outra modernidade. São Paulo: Editora 34, 2016.

BOHOLM, A. Anthropology and risk. New York: Routledge, 2015.

BRASIL. CÂMARA DOS DEPUTADOS. Sistema de Incentivos a Serviços Ambientais. 2016. Disponível em: https://www2.camara.leg.br/atividadelegislativa/comissoes/comissoes-permanentes/cindra/documentos/magaly-imc. Acesso em: 05 de março de 2019.

BRASIL. SENADO FEDERAL. Decreto n 8.843 de 26 de julho de 1911: Crêa a reserva florestal do Território do Acre. Presidente Hermes da Fonseca. Brasília: Subsecretaria de Informações, 1911. Disponível em: https://www2.camara.leg.br/legin/fed/decret/ 1910-1919/decreto-8843-26-julho-1911579259-republicacao-102184-pe.html. Acesso em: 03 de março de 2019.

BROSE, M. E. Inovação na gestão pública subnacional: reflexões sobre a estratégia de desenvolvimento do Acre. Revista de Administração Pública, v. 48, n. 2, p. 277-294, 2014.

CÂNDIDO, F. de M. BR 364: análise da sustentabilidade das medidas mitigadoras e compensatórias na TI Colônia 27. 2012. Dissertação (Mestrado em Desenvolvimento Sustentável). - Centro de Desenvolvimento Sustentável. Universidade de Brasília, 2012.

CARVALHO, K.M. (2019). Governança de riscos hidro-climáticos na Amazônia sul-ocidental: em busca de um modelo sistêmico alternativo. 2019. Tese (Doutorado em Administração). - Núcleo de Pós-Graduação em Administração. Universidade Federal da Bahia, 2019.

COSTA, S.; ALONSO, A.; TOMIOKA, S. A Re-significação das Tradições: o Acre entre o rodoviarismo e o socioambientalismo. Cadernos IPPUR, Rio de Janeiro, v. 13, n. 2, p. 115-131, 1999.

CRESWELL, J. W.; CRESWELL, J. D. Research design: qualitative, quantitative, and mixed methods approaches. London: Sage publications, 2017.

DELGADO, A. C. T. Seringueiros: da luta pela terra à proteção da floresta tropical: um estudo sobre o processo de transnacionalização do movimento. 2006. 152 f. Tese (Doutorado em Relações Internacionais). - Instituto de Relações Internacionais, Pontífícia Universidade Católica do Rio de Janeiro, 2007.

DUCHELLE, A. E. et al. Acre's State System of Incentives for Environmental Services (SISA), Brazil. In: SILLS, E.O. et al, eds. 2014. REDD+ on the ground: a case book of subnational initiatives across the globe. Bogor: CIFOR, 2014.

ESTADÃO. Cheia no Acre já causa prejuízo de cerca de $\mathbf{R} \$ 203$ milhões, diz governo. 2016. Disponível em: http://brasil.estadao.com.br/noticias/geral,cheia-no- 
acre-ja-causa-prejuizo-de-cerca-de-r-203-milhoes-diz-governo,1149855. Acesso em: 28 jul. 2017.

REVISTA EXAME. Acre decreta estado de emergência por incêndios em florestas. 2019. Disponível em: https://exame.abril.com.br/brasil/acre-decreta-estado-deemergencia-por-incendios-em-florestas/ Acesso em: 10 oct. 2019.

GIDDENS, A. The consequences of modernity. New York: John Wiley \& Sons, 2013.

GLOBO. Enchente histórica faz $3^{\mathbf{a}}$ cidade do Acre decretar situação de emergência. 2017. Disponível em: http://g1.globo.com/ac/cruzeiro-do-sul-regiao/noticia/2017/02/ enchente-historica-faz-3-cidade-do-acre-decretar-situacao-de-emergencia.html. Acesso em: 15 ago. 2017.

GOVERNORS CLIMATE TASK FORCE. GCF task force. 2019. Disponível em: https://www.gcftf.org/about. Acesso em: 06 jun. 2019.

HOELLE, J. Rainforest Cowboys: The Rise of Ranching and Cattle Culture in Western Amazonia. Austin: University of Texas Press, 2015

HOPKIN, P. Fundamentals of risk management: understanding, evaluating and implementing effective risk management. London: Kogan Page Publishers, 2017.

IBGE. Síntese dos Indicadores Econômicos do Acre. 2018. Disponível em: https://cidades.ibge.gov.br/brasil/ac/pesquisa/45/62585. Acesso em: 13 nov. 2018.

IPCC. Cambio climático 2013 - base de ciência física. 2013. Disponível em: https://www.ipcc.ch/news_and_events/docs/ar5/ar5_wg1_headlines_es.pdf. Acesso em: 30 jan. 2017.

LUHMANN et al. The idea of the public sphere: a reader. Idaho Falls: Lexington books, 2010.

LUHMANN, N. Communication and social order: risk: a sociological theory. New Jersey: Transaction Publishers, 2005.

LUHMANN, N. Economía de la sociedad. Ciudad de Mexico: Herder Editorial, 2018

LUHMANN, N. Introduction to systems theory. Cambridge: Polity, 2013.

LUHMANN, N. O direito da sociedade. São Paulo: Martins Fontes, 2016.

LUHMANN, N. Organización y decisión. Autopoiesis, accion y entendimento comunicativo. Barcelona: Anthropos Editorial, 2012.

LUHMANN, N. Politics as a social system. In: The diferentiation of society.

New York: Columbia University Press, 1982.

LUPTON, D. Risk. 2 ed. London: Routledge, 2013.

MENDOZA, E. R. H. et al. Adaptation to Climate Change in the Transboundary MAP Region. Hg. v. IS RIVERS, 2015.

MINISTÉRIO DO MEIO AMBIENTE. Conselho Nacional de Recursos Hídricos.

Moção n. 59, de 20 de setembro de 2011. Disponível em:

http://www.cnrh.gov/br/inserir-documentos-nos-artigos/mocoes/1486-mocao-n-59-de20-de-setembro-de-2011/file_Acesso em: 10 mar. 2018

NEVES, R. F. Acoplamento estrutural, fechamento operacional e processos sobrecomunicativos na teoria dos sistemas sociais de Niklas Luhmann. 146f. 2005. 
Tese (Doutorado). Programa de Pós-Graduação em Sociologia. Universidade de São Paulo, São Paulo, 2005.

OTCA. Amazon waters: 10 research projects on the world's largest river basin. 2018. Disponível em: http://www.otca-oficial.info/assets/documents/20181022/ 94b35b78327fb57880022313327a00f3.pdf Acesso em: 10 mar.2019

PEREIRA, D. M.; SZLAFSZTEIN, C. F. Ameaças e desastres naturais na Amazônia Sul Ocidental: análise da bacia do Rio Purus. Raega - O Espaço Geográfico em Análise, v. 35, p. 68-94, 2016.

PERZ, Stephen et al. Road building, land use and climate change: prospects for environmental governance in the Amazon. Philosophical Transactions of the Royal Society B: Biological Sciences, v. 363, n. 1498, p. 1889-1895, 2008.

PERZ, Stephen G. et al. Scientists and Stakeholders, Data and Diagnostics: Crossing Boundaries for Modeling the Impacts of Highway Paving in a Tri-national Frontier in the Amazon. In: Collaboration Across Boundaries for Social-Ecological Systems Science. Palgrave Macmillan, Cham, p. 327-359, 2019.

PONTES, C. J. F. O primeiro ciclo da borracha no acre: da formação dos seringais ao grande colapso. South American Journal of Basic Education, Technical and Technological, v. 1, n. 1, 2014.

RODRIGUES, L. P.; NEVES, F. M. Niklas Luhmann: a sociedade como sistema. Porto Alegre: Edipucrs, 2012, 132 p.

TOSTES, J. de O. Sinergismo entre eventos climáticos extremos, desmatamento e aumento da suscetibilidade a incêndios florestais no Estado do Acre. 2016. 138f. Tese (Doutorado em Ciências Ambientais e Florestais) - Programa de Pós-Graduação em Ciências Ambientais e Florestais, Universidade Federal Rural do Rio de Janeiro.

VALOR ECONÔMICO. Pobreza extrema avança e é recorde em 9 estados. 2018. Disponível em: https://www.valor.com.br/brasil/5912587/extrema-pobreza-avanca-e-erecorde-em-9-estados. Acesso em: 14 mar. 2019.

VIANA, Hélio. História das fronteiras do Brasil, Rio de Janeiro, Edição da Biblioteca Militar. 1948. Disponível em: https://wrm.org.uy/pt/files/2018/07/SchattenberichtREM-Druckversion-PT-BR_low.pdf. Acesso em 25 mar. 2019.

VIDAL, J. P. Sistemas y ser humano: pensamiento autorreferencial en la Amazonia. Barcelona: Icaria Editorial, 2015.

VIDAL, J. P. A teoria neosistêmica de Niklas Luhmann e a noção de autopoiese comunicativa nos estudos organizacionais. Cadernos EBAPE. BR, v. 15, n. 2, p. 274$291,2017$.

YIN, R. K. Estudo de Caso: planejamento e métodos. Porto Alegre: Bookman Editora, 2015.

Recebido em: 10/10/2021

Aprovado em: 10/11/2021

Publicado em: 18/11/2021 